\title{
Identifikasi dan Telaah Pemanfaatan Sumber Daya Genetik Buah-buahan Lokal untuk Meningkatkan Integrasi Pertanian dan Pariwisata di Bali
}

\author{
Identification and Study of Utilization of Genetic Resources of Local Fruits \\ to Improve Integration of Agriculture and Tourism in Bali \\ I Nyoman Rai ${ }^{1 *}$, Gede Wijana ${ }^{1}$, I Putu Sudana ${ }^{2}$, I Wayan Wiraatmaja ${ }^{1}$, \\ Cok. Gede Alit Semarajaya ${ }^{3}$, dan Ni Komang Alit Astiari ${ }^{4}$
}

Diterima 28 Januari 2016/Disetujui 16 Maret 2016

\begin{abstract}
The rapid growth of tourism in Bali raises new issues i.e. the decline of the agricultural sector. A model of development of integration of agriculture and tourism is required to avoid further imbalance in the development of tourism and agriculture. The objective of this study was to identify and study utilization of genetic resources of local fruits in order to improve agricultural and tourism integration. The research was conducted from March to December 2015 throughout regencies in Bali, using survey method to identify the species and sub-species of local fruits, its utilization, harvest time, and superior fruits of each regency. Definition of local fruit in this study is all species and sub-species of fruit plant found in Bali, either cultivated or wild. The results showed that there were 41 species with 149 sub-species of local fruits identified. Availability of local fruits was generally still seasonal. The harvest season was dominant from December to March. Fruits were used for local consumption, exports, inter-island trade, and material for rituals and culture and for tourism market. Utilization of local fruit for tourism was still limited, i.e for fresh fruit consumption (snake fruit, wani, banana, mango, orange, papaya, water melon, melon and mangosteen), for juice (passion fruit, manggo, melon, water melon, guava, strawberry, wani); raw material for wine (snake fruit, grape), raw material for massage/Spa (lemon, pineapple, avocado, papaya, strawberry, star fruit), and for agrotourism object (strawberry, snake fruit, orange and mangosteen). We suggested that effort was required to increase the utilization of local fruits for tourism activities so that it increased the welfare of the farming community in Bali.
\end{abstract}

Ke y word: genetic resources, local fruit, integration, agriculture, tourism

\begin{abstract}
ABSTRAK
Pesatnya perkembangan pariwisata di Bali memunculkan masalah baru yaitu semakin terdesaknya sektor pertanian. Untuk menghindari semakin tidak seimbangnya antara sektor pariwisata dan pertanian dikembangkanlah model pembangunan pertanian terintegrasi dengan pariwisata. Penelitian ini bertujuan melakukan identifikasi dan telaah pemanfaatan sumber daya genetik buah-buahan lokal untuk meningkatkan integrasi pertanian dan pariwisata. Penelitian dilakukan dari Maret sampai Desember 2015 di seluruh kabupaten di Bali, menggunakan metode survei untuk mengidentifikasi spesies dan sub-spesies sumber daya genetik buah-buahan lokal, pemanfaatannya, musim panen, dan buah unggulan kabupaten. Batasan buah lokal dalam penelitian ini adalah semua spesies dan sub-spesies buah-buahan yang ada di Bali, baik dibudidayakan atau liar. Hasil penelitian menunjukkan teridentifikasi sebanyak 41 spesies dan 149 sub-spesies buahbuahan lokal. Lokasi tumbuhnya sebagian besar tersebar hampir di seluruh kabupaten/kota di Bali seperti jeruk Bali, salak, pisang, wani, mangga, manggis, durian, jambu biji, dan nangka, tetapi ada yang hanya dibudidayakan atau tumbuh pada lokasi spesifik tertentu seperti stroberi, kawista, anggur, leci, dan mundu. Ketersediaan buah umumnya masih bersifat musiman, dengan musim

\footnotetext{
1) Program Studi Agroekoteknologi, Faperta Universitas Udayana, Denpasar ${ }^{*}$

${ }^{2)}$ Program Studi Industri Perjalanan Wisata, Fakultas Pariwisata Universitas Udayana, Denpasar

${ }^{3)}$ Program Studi Arsitektur Pertamanan, Faperta Universitas Udayana, Denpasar

4) Program Studi Agroteknologi, Faperta Universitas Warmadewa, Denpasar

Alamat Korespondensi: Perumahan Padang Asri Blok IX/14, Jl. Gunung Tangkuban Perahu, Desa Padangsambian Kelod,

Kecamatan Denpsar Barat, Bali 80117. Telp. 0361-430238,Fax:0361-702801, E-mail:inrai_fpunud@yahoo.com
} 
panen dominan dari Desember sampai Maret. Produksi buah-buahan lokal Bali dimanfaatkan untuk konsumsi lokal, komoditas ekspor, perdagangan antar pulau, keperluan ritual adat dan budaya, dan pasar pariwisata. Pemanfaatan untuk pariwisata masih relatif terbatas, meliputi: (1) hasil buah untuk konsumsi segar (fresh fruit) seperti salak, wani, pisang, mangga, jeruk, pepaya, semangka, melon dan manggis; (2) hasil buah untuk bahan juice (markisa, mangga, melon, semangka, stroberi, wani); (3) hasil buah untuk bahan wine (salak, anggur), (4) bagian buah, daun, atau bagian lainnya untuk massage/spa (jeruk lemon, nenas, avokad, pepaya, stroberi, belimbing wuluh); dan (5) kebun buah untuk agrowisata (stroberi, salak, jeruk, dan manggis). Berdasarkan hasil penelitian ini perlu ada upaya nyata meningkatkan pemanfaatan buah-buahan lokal untuk pariwisata agar kesejahteraan petani buah-buahan semakin meningkat.

Kata kunci: buah lokal, integrasi, pariwisata, pertanian, sumber daya genetik

\section{PENDAHULUAN}

Provinsi Bali masih menjadi tujuan wisata utama di Indonesia yang terus berkembang. Pesatnya perkembangan sektor pariwisata memberikan kontribusi yang sangat signifikan bagi perekonomian Bali, ditunjukkan oleh tingginya kontribusi sektor pariwisata, hotel dan restoran terhadap PDRB Bali selama 3 tahun terakhir (2011-2013) yaitu 29.89\%. Kontribusi sektor pertanian pada periode yang sama hanya 19.17\% (BPS Bali, 2014).

Komersialisme Bali yang menonjolkan pariwisata secara berlebihan berdampak pada tidak berkembangnya ekonomi Bali yang lain secara seimbang. Perkembangan yang asimetris dengan dominasi sektor pariwisata telah berdampak pada termarginalisasinya sektor partanian. Padahal pertanian bukan hanya sebagai pilar penting dalam mendukung keberhasilan pariwisata, tetapi juga sebagai sektor strategis yang harus tetap dijaga karena merupakan hajat hidup bagi sebagian besar masyarakat Bali dan instrumen penting dalam menjaga keberlanjutan industri pariwisata. Disadari atau tidak, sesungguhnya pariwisata Bali sangat tergantung pada pertanian. Bali dikenal dan dikagumi karena nilai budaya agrarisnya yang unik dan kondisi alamnya yang menarik. Keunikan budaya dan keindahan alam tersebut akan tetap ajeg apabila pertanian tetap dijaga, dan ini dapat tercapai apabila sektor pertanian itu sendiri mampu memberi kesejahteraan bagi masyarakatnya. Untuk mencapai tujuan tersebut dikembangkanlah model pembangunan partanian yang disinergikan dengan pariwisata. Goodwin (2008) dan Prayogi dan Yuni (2013) mengemukakan bahwa sinergi pembangunan pertanian dan pariwisata bertujuan agar sektor pariwisata memberikan multiplier effect pada sektor pertanian sehingga kesejahteraan pelaku pertanian meningkat. Dengan demikian, sektor pariwisata dan pertanian dapat terjamin keberlanjutannya.

Integrasi pertanian dan pariwisata di Bali sejak satu dekade terakhir telah dikembangkan dalam berbagai bentuk seperti pengembangan pariwisata pada sistem subak, pemanfaatan view dan aktivistas pertanian (tanaman pangan, hortikultura, perkebunan, peternakan, dan perikanan) untuk agrowisata atau agro-ekowisata. Kegiatan-kegiatan tersebut telah memberikan dampak positif terhadap pendapatan ekonomi petani dan tumbuhnya persepsi positif terhadap pariwisata di kalangan masyarakat pedesaan (Windia et al., 2011; Sumiyati et al., 2011). Oleh karena itu, model pembangunan pertanian terintegrasi dengan pariwisata perlu semakin didorong implementasinya melalui pendekatan sinergiskomplementaris agar terjadi hubungan saling menguntungkan (Nurisjah, 2001; Budiarti et al., 2013; Budiarti dan Listyanti, 2015). Dengan semakin, meningkatnya integrasi pertanian dan pariwisata, dalam jangka panjang pariwisata diharapkan dapat berperan sebagai pendorong sektor pertanian agar selalu meningkatkan kuantitas, kualitas dan kontinuitas produk (Sudana dan Mahadewi, 2015), serta melestarikan lingkungan untuk mewujudkan green tourism dan sustainable tourism (Goodwin, 2008; Suyastri, 2012).

Sumber daya genetik buah-buahan lokal merupakan salah satu potensi besar yang belum diberdayakan dalam rangka mewujudkan integrasi pertanian dan pariwisata. Sumber daya genetik atau plasma nutfah berdasarkan Peraturan Menteri Negara Lingkungan Hidup No. 29 tahun 2009 adalah bahan tanaman, 
hewan dan jasad renik, yang mempunyai kemampuan untuk menurunkan sifat dari generasi ke generasi berikutnya, dapat dimanfaatkan untuk kepentingan pemuliaan dalam mengembangkan variates baru. Dalam penelitian ini batasan buah lokal adalah semua spesies dan sub-spesies buah-buahan yang ada di Bali, baik yang dibudidayakan atau tumbuh liar.

Buah-buahan di Bali tidak hanya bernilai ekonomi untuk konsumsi domestik, tetapi juga bernilai sosial budaya untuk kegiatan ritual keagamaan, memenuhi kebutuhan pariwisata, bahan Spa (massage), perdagangan antar pulau, dan ekspor. Namun, menurut Adelianie (2015) peluang pasar buah-buahan yang besar di Bali belum dimanfaatkan dengan baik oleh produsen buah lokal yang ditunjukkan oleh pamor buah lokal semakin menurun sementara buah impor semakin menjamur tidak hanya di super market dan pasar pariwisata, tetapi telah merambah sampai ke pasar tradisional dan warung-warung kecil di pedesaan.

Terdesaknya keberadaan buah-buahan lokal mendorong Pemerintah Provinsi Bali membuat regulasi dengan mengeluarkan Peraturan Daerah Provinsi Bali Nomor 3 Tahun 2013 tentang Perlindungan Buah Lokal. Tujuan dari diberlakukannya Perda tersebut adalah agar terjadi penguatan, pemberdayaan dan perlindungan sumber daya genetik buahbuahan lokal melalui kegiatan pengembangan buah lokal terintegrasi dengan industri pariwisata. Terkait dengan hal itu, penelitian ini dilakukan dengan tujuan mengidentifikasi spesies dan sub-spesies buah-buahan lokal yang ada di Bali, baik yang dibudidayakan atau tumbuh liar, dan menelaah pemanfaatannya untuk meningkatkan integrasi pertanian dan pariwisata.

\section{BAHAN DAN METODE}

Penelitian dilakukan di seluruh kabupaten di Bali dari bulan Maret sampai Desember 2015. Buah-buahan lokal diinventarisasi dan diidentifikasi melalui metode survei lapangan untuk menemukan semua spesies dan sub-spesies, baik yang dibudidayakan maupun yang tumbuh liar (tidak/belum dibudidayakan). Disamping itu, diamati pula pemanfaatannya, musim/waktu panen, dan buah lokal komersial unggulan kabupaten.

Cara menentukan buah lokal komersial unggulan kabupaten dihitung menggunakan metode Location Quotient ( $L Q)$ mengikuti metode Isserman (1977) dan Miller et al. (1991) dengan formula:

$$
L_{i}{ }^{k j}=\frac{X_{i}^{k j} / X^{k j}}{X_{i}^{p} / X^{p}}
$$

Dimana :

$$
\begin{array}{ll}
\mathrm{LQ}_{\mathrm{i}}^{\mathrm{kj}} & =\mathrm{LQ} \text { spesies buah } \mathrm{i} \text { di wilayah } \\
& \text { kabupaten } \\
\mathrm{X}_{\mathrm{i}}^{\mathrm{kj}} & =\begin{array}{l}
\text { jumlah produksi spesies buah } \mathrm{i} d \mathrm{~d} \\
\text { wilayah kabupaten }
\end{array} \\
\mathrm{X}^{\mathrm{kj}} & =\begin{array}{l}
\text { jumlah produksi agregat buah di } \\
\text { wilayah kabupaten }
\end{array} \\
\mathrm{X}_{\mathrm{i}}{ }^{\mathrm{p}} & =\begin{array}{l}
\text { jumlah produksi spesies buah i di } \\
\text { wilayah provinsi }
\end{array} \\
\mathrm{X}^{\mathrm{p}} & =\begin{array}{l}
\text { jumlah produksi agregat buah di } \\
\text { wilayah provinsi }
\end{array}
\end{array}
$$

Bila LQ $\geq 1$ maka tergolong spesies buah unggulan kabupaten.

Jumlah produksi buah-buahan lokal yang digunakan untuk mengitung nilai LQ seperti formula di atas adalah data produksi rata-rata selama 5 tahun terakhir (2010-2014) dari BPS Bali (2014) dan data statistik setiap kabupaten. Hasil identifikasi spesies dan subspesies buah-buahan lokal, pemanfaatannya, musim panen dan spesies buah lokal unggulan kabupaten yang diperoleh ditabulasi dan dianalisis secara deskriptif.

\section{HASIL DAN PEMBAHASAN}

Survei berhasil mengidentifikasi 41 spesies dan 149 sub-spesies buah-buahan lokal. Dari 41 spesies buah tersebut, sebanyak 31 spesies merupakan buah yang dibudidayakan dan 10 spesies lainnya tumbuh liar (tidak/belum dibudidayakan) dengan 7 spesies diantaranya tergolong langka, yaitu bidara/ bekul (Zyzyphus jujuba), dewandaru/buah dewa (Eugenia uniflora L.) gowok/kaliasem (Syzygium polycephalum Mig.), jamblang/juwet (Eugenia cumini Merr.), kawista/kwista (Feronia acidissima L.), kecapi/sentul (Sandoricum koetjape Merr.), dan mundu/badung (Garcinia dulcis Roxb. kurz) (Tabel 1). 
Tabel 1. Spesies dan sub-spesies buah-buahan lokal Bali dan pemanfaatannya

\begin{tabular}{|c|c|c|c|c|c|c|c|c|c|c|}
\hline \multirow{2}{*}{ No. } & \multirow{2}{*}{$\begin{array}{l}\text { Nama Spesies Buah (Nama } \\
\text { Indonesia/Bali/Latin/Inggris) }\end{array}$} & \multirow{2}{*}{$\begin{array}{c}\text { Jumlah } \\
\text { sub- } \\
\text { spesies }\end{array}$} & \multicolumn{5}{|c|}{ Pemanfaatan $^{1)}$} & \multicolumn{3}{|c|}{ Keterangan $^{2)}$} \\
\hline & & & A & $\mathrm{B}$ & $\mathrm{C}$ & $\mathrm{D}$ & $\mathrm{E}$ & $\mathrm{F}$ & $\mathrm{G}$ & $\mathrm{H}$ \\
\hline 1. & Anggur/Anggur/Vitis vinivera L./Grape & 2 & $\sqrt{ }$ & $\sqrt{ }$ & & $\sqrt{ }$ & $\sqrt{ }$ & $\sqrt{ }$ & & \\
\hline 2. & Avokad/Apokat/Persea Americana Mill./Avocado & 3 & $\sqrt{ }$ & $\sqrt{ }$ & & & $\sqrt{ }$ & $\sqrt{ }$ & & \\
\hline 3. & Belimbing/Blimbing/Averrhoa carambola L./Starfruit & 2 & $\sqrt{ }$ & & & $\sqrt{ }$ & $\sqrt{ }$ & $\sqrt{ }$ & & \\
\hline 4. & Bidara/Bekul/Zyzyphus jujube/ Indian plum & 2 & $\sqrt{ }$ & & & & & & $\sqrt{ }$ & $\sqrt{ }$ \\
\hline 5. & Buni/Boni/Antidesma bunius/Currant tree & 2 & $\sqrt{ }$ & & & $\sqrt{ }$ & & & $\sqrt{ }$ & \\
\hline 6. & $\begin{array}{l}\text { Ceremai/Cereme/Phyllantus acidus L./Malay } \\
\text { gooseberry }\end{array}$ & 1 & $\sqrt{ }$ & & & $\sqrt{ }$ & & $\sqrt{ }$ & & \\
\hline 7. & Delima/Dlemo/Punica granatum L./Pomegranate & 3 & $\sqrt{ }$ & & & $\sqrt{ }$ & & $\sqrt{ }$ & & \\
\hline 8. & $\begin{array}{l}\text { Dewandaru/Buah Dewa/Eugenia uniflora L./ } \\
\text { Suriname cherry }\end{array}$ & 1 & $\sqrt{ }$ & & & & & & $\sqrt{ }$ & $\sqrt{ }$ \\
\hline 9. & Duku/Ceroring/Lancium domesticum Corr./Duku & 2 & $\sqrt{ }$ & & & $\sqrt{ }$ & $\sqrt{ }$ & $\sqrt{ }$ & & $\sqrt{ }$ \\
\hline 10. & Durian/Duren/Durio zibhetinus Murr/Durian & 4 & $\sqrt{ }$ & $\sqrt{ }$ & & $\sqrt{ }$ & $\sqrt{ }$ & $\sqrt{ }$ & & \\
\hline 11. & $\begin{array}{l}\text { Gowok/Kaliasem/Syzygium polycephalum Mig./ } \\
\text { Kaliasem }\end{array}$ & 1 & $\sqrt{ }$ & & & & & & $\sqrt{ }$ & $\sqrt{ }$ \\
\hline 12. & Jamblang/Juwet/Eugenia cumini Merr/Java plum & 2 & $\sqrt{ }$ & & & $\sqrt{ }$ & & & $\sqrt{ }$ & $\sqrt{ }$ \\
\hline 13. & Jambu Air/Nyamber/Syzygium aqueum/Water apple & 2 & $\sqrt{ }$ & & & $\sqrt{ }$ & $\sqrt{ }$ & $\sqrt{ }$ & & \\
\hline 14. & Jambu Biji/Sotong/Psidium guajava L./Guava & 9 & $\sqrt{ }$ & & & $\sqrt{ }$ & $\sqrt{ }$ & $\sqrt{ }$ & & \\
\hline 15. & $\begin{array}{l}\text { Jambu Bol/Nyambu Rata/Syzygium malaccensis L./ } \\
\text { Malay Apple }\end{array}$ & 2 & $\sqrt{ }$ & & & & & $\sqrt{ }$ & & \\
\hline 16. & Jeruk/Juuk/Citrus sp./Orange & 7 & $\sqrt{ }$ & $\sqrt{ }$ & & $\sqrt{ }$ & $\sqrt{ }$ & $\sqrt{ }$ & & \\
\hline 17. & $\begin{array}{l}\text { Jeruk Besar/Jeruti/Citrus grandis (L.) } \\
\text { Osbeck/Pomelo }\end{array}$ & 3 & $\sqrt{ }$ & $\sqrt{ }$ & & $\sqrt{ }$ & $\sqrt{ }$ & $\sqrt{ }$ & & \\
\hline 18. & Kawista/Kwista/Feronia acidissima L./Java cola & 2 & $\sqrt{ }$ & & & $\sqrt{ }$ & & & $\sqrt{ }$ & $\sqrt{ }$ \\
\hline 19. & Kecapi/Sentul/Sandoricum koetjape Merr/Sentol & 1 & $\sqrt{ }$ & & & $\sqrt{ }$ & & & $\sqrt{ }$ & $\sqrt{ }$ \\
\hline 20. & Kedondong/Kdondong/Spondias pinnata/Ambarella & 2 & $\sqrt{ }$ & & & & & $\sqrt{ }$ & & \\
\hline 21. & Kesemek/Semek/Diospyros kaki L./Persimon & 1 & $\sqrt{ }$ & & & & & & $\sqrt{ }$ & \\
\hline 22. & Lechi/Lici/Litchi chinensis Sonn/Lichee & 1 & $\sqrt{ }$ & & & $\sqrt{ }$ & & $\sqrt{ }$ & & $\sqrt{ }$ \\
\hline 23. & Mangga/Poh/Mangifera sp./Manggo & 8 & $\sqrt{ }$ & $\sqrt{ }$ & & $\sqrt{ }$ & $\sqrt{ }$ & $\sqrt{ }$ & & $\sqrt{*}$ \\
\hline 24. & $\begin{array}{l}\text { Manggis/Manggis/Garcinia mangostana L./ } \\
\text { Mangosteen }\end{array}$ & 1 & $\sqrt{ }$ & $\sqrt{ }$ & $\sqrt{ }$ & $\sqrt{ }$ & $\sqrt{ }$ & $\sqrt{ }$ & & \\
\hline 25. & $\begin{array}{l}\text { Markisa/Anggur Markisa/Passiflora edulis/Passion } \\
\text { fruit }\end{array}$ & 3 & $\sqrt{ }$ & & & & $\sqrt{ }$ & $\sqrt{ }$ & & $\sqrt{ } *$ \\
\hline 26. & Melon/Melon/Cucumis melo/Melon & 3 & $\sqrt{ }$ & & & & $\sqrt{ }$ & $\sqrt{ }$ & & \\
\hline 27. & Menteng/Kepundung/Baccaurea recemosa/Menteng & 1 & $\sqrt{ }$ & & & $\sqrt{ }$ & & $\sqrt{ }$ & & $\sqrt{ }$ \\
\hline 28. & $\begin{array}{l}\text { Mundu/Badung/Garcinia dulcis (Roxb) kurz/ } \\
\text { Moendoe }\end{array}$ & 1 & $\sqrt{ }$ & & & $\sqrt{ }$ & & & $\sqrt{ }$ & $\sqrt{ }$ \\
\hline 29. & Nangka/Nangke/Artocarpus heterophyllus/Jack fruit & 2 & $\sqrt{ }$ & & & $\sqrt{ }$ & $\sqrt{ }$ & $\sqrt{ }$ & & \\
\hline 30. & $\begin{array}{l}\text { Nenas/Manas/Ananas commosus (L.) } \\
\text { Merr./Pineapple }\end{array}$ & 2 & $\sqrt{ }$ & & & $\sqrt{ }$ & $\sqrt{ }$ & $\sqrt{ }$ & & \\
\hline 31. & Pepaya/Gedang/Carica papaya L./Papaya & 5 & $\sqrt{ }$ & & & $\sqrt{ }$ & $\sqrt{ }$ & $\sqrt{ }$ & & \\
\hline 32. & Pisang/Biu/Musa sp./Banana & 23 & $\sqrt{ }$ & & & $\sqrt{ }$ & $\sqrt{ }$ & $\sqrt{ }$ & & $\sqrt{ } *$ \\
\hline 33. & $\begin{array}{l}\text { Rambutan/Rambutan/Nephelium lappacceum L./ } \\
\text { Rambutan }\end{array}$ & 5 & $\sqrt{ }$ & $\sqrt{ }$ & & & $\sqrt{ }$ & $\sqrt{ }$ & & \\
\hline 34. & Salak/Salak/Salaca edulis Reinw/Snake fruit & 8 & $\sqrt{ }$ & $\sqrt{ }$ & $\sqrt{ }$ & $\sqrt{ }$ & $\sqrt{ }$ & $\sqrt{ }$ & & $\sqrt{*}$ \\
\hline 35. & Sawo/Sabo/Manilkara achras Mill./Sapodilla & 3 & $\sqrt{ }$ & & & $\sqrt{ }$ & $\sqrt{ }$ & $\sqrt{ }$ & & \\
\hline 36. & Semangka/Semangke/Citrullus lanatus/Water melon & 2 & $\sqrt{ }$ & & & & $\sqrt{ }$ & $\sqrt{ }$ & & \\
\hline 37. & Sirsak/Srikaya Jawa/Annoma muricata L./Soursop & 1 & $\sqrt{ }$ & & & & $\sqrt{ }$ & $\sqrt{ }$ & & \\
\hline 38. & Srikaya/Silik/Annona squamosa/Sugar apple & 2 & $\sqrt{ }$ & & & & $\sqrt{ }$ & $\sqrt{ }$ & & \\
\hline 39. & Stroberi/Stroberi /Fragaria sp./Strawberry & 1 & $\sqrt{ }$ & & & & $\sqrt{ }$ & $\sqrt{ }$ & & \\
\hline 40. & $\begin{array}{l}\text { Terong Belanda/Tuung Belanda/(Solanum betaceum/ } \\
\text { Tamarilla }\end{array}$ & 1 & $\sqrt{ }$ & & & & & & $\sqrt{ }$ & \\
\hline 41. & Wani/Wani/Mangifera caesia Jack/White manggo & 22 & $\sqrt{ }$ & $\sqrt{ }$ & $\sqrt{ }$ & $\sqrt{ }$ & $\sqrt{ }$ & $\sqrt{ }$ & & \\
\hline
\end{tabular}

Keterangan: ${ }^{1)}$ : $\mathrm{A}=$ konsumsi lokal, $\mathrm{B}=$ perdagangan antar pulau, $\mathrm{C}=$ ekspor, $\mathrm{D}=$ ritual adat dan budaya, $\mathrm{E}=$ pariwisata ${ }^{2)}: \mathrm{F}=$ dibudidayakan, $\mathrm{G}=$ liar, $\mathrm{H}=$ langka $(\sqrt{ } *=$ ada sub-spesies dalam spesies tersebut yang tergolong langka). 
Beberapa sub-spesies dari spesies buah lokal yang dibudidayakan juga tergolong langka, yaitu pada spesies mangga sub-spesies yang tergolong langka ialah mangga eni/poh eni (Mangifera odorata Griffith) dan mangga pakel/poh pakel (Mangifera foetida Lour.), pada spesies markisa sub-spesies yang tergolong langka markisa besar/melisah (Passiflora quadrangularis), pada spesies pisang sub-spesies yang tergolong langka pisang seribu/biu siu (Musa chiliocarpa), dan pisang gunting/biu, gunting (Musa sp.), dan pada spesies salak sub-spesies yang tergolong langka yaitu salak mangku/salak turis (Salacca zalacca var. Mangku), salak getih/ salak barak (Salacca zalacca var. Getih), salak beringin/salak bingin (Salacca zalacca var. Beringin), dan salak sudamala/ salak sudemale (Salacca zalacca var. Sudamala). Kriteria langka dalam penelitian ini ditetapkan menurut Milner-Gulland (1992) dan Gardenfors et al. (2001), bahwa suatu organisme dapat ditetapkan sebagai kategori langka (endangered) apabila populasinya kurang dari 10000 karena sempitnya area endemik dan atau habitat yang terfragmentasi, atau secara kualitatif jumlah populasinya terus berkurang dengan cepat sehingga sulit mengembalikan secara alami ke jumlah semula. Hasil survei ini menunjukkan bahwa beberapa spesies dan sub-spesies buahbuahan lokal perlu segera dikonservasi untuk menghindari dari ancaman kepunahan.

Hasil wawancara dengan para serati, yaitu orang yang ahli dalam membuat sarana upacara untuk kegiatan ritual adat dan budaya (bahasa Bali: banten), seluruh buah-buahan lokal yang tergolong langka di atas walaupun tidak diperdagangkan secara komersial, tetapi sangat dibutuhkan untuk kelengkapan upacara adat Panca Yadnya (lima persembahan suci), yaitu Dewa Yadnya (persembahan suci kepada para Dewa), Rsi Yadnya (persembahan suci kepada para Rsi/Guru), Manusa Yadnya (persembahan suci untuk kesejahteraan manusia), Pitra Yadnya (persembahan suci kepada leluhur), dan Butha Yadnya (persembahan suci kepada bhutakala atau kekuatan yang bersifat negatif). Menurut Mace dan Lande (1991), upaya konservasi perlu segera diberikan kepada spesies yang mungkin berada dalam keadaan terancam atau mendekati kepunahan, meski tidak termasuk ke dalam status terancam. Upaya ini penting agar tidak terjadi kepunahan sehingga mereduksi kekayaan sumber daya genetik yang dimiliki dan menyulitkan untuk mendapatkan bahan sarana upacara adat dan budaya.

Hasil survei menunjukkan, buah-buahan lokal Bali dimanfaatkan untuk berbagai kepentingan, yaitu untuk konsumsi lokal, perdagangan antar pulau, komoditas ekspor, memenuhi keperluan ritual adat dan budaya, dan pasar pariwisata. Pemanfaatan untuk kegiatan pariwisata masih relatif terbatas, yaitu dalam bentuk: (1) hasil buah untuk konsumsi segar (fresh fruit) seperti salak, wani, pisang, mangga, jeruk, pepaya, melon, semangka dan manggis; (2) hasil buah untuk bahan juice (markisa, mangga, melon, semangka, jambu biji, stroberi, wani); (3) hasil buah untuk bahan wine (salak, anggur), (4) bagian buah, daun, atau bagian lainnya untuk massage/spa (jeruk lemon, nenas, avokad, pepaya, stroberi, belimbing wuluh); dan (5) kebun buah-buahan untuk agrowisata (stroberi, salak, jeruk, dan manggis). Hasil serupa didapatkan oleh Dinata et al. (2011) bahwa pemanfaatan hasil pertanian oleh pasar pariwisata di Bali masih sangat rendah sehingga perlu dilakukan pemberdayaan petani melalui pengembangan pariwisata berbasis pertanian (agrowisata). Hal ini juga sejalan dengan hasil penelitian Routray dan Malkanthi (2011) di Srilangka, bahwa agrowisata perlu dikembangkan melalui peningkatan peran serta masyarakat dan dukungan pemerintah untuk mendorong petani dapat mengembangkan pariwisata berbasis masyarakat.

Lokasi tumbuh berbagai spesies buahbuahan lokal Bali yang teridentifikasi sebagian besar tersebar hampir di seluruh kabupaten/ kota di Bali karena tidak menuntut syarat tumbuh (tanah dan iklim) yang spesifik seperti jeruk Bali, salak Bali, salak Gula Pasir, pisang, wani, mangga, manggis, durian, jambu biji, dan nangka, tetapi banyak pula yang hanya dibudidayakan atau tumbuh pada lokasi spesifik tertentu karena membutuhkan syarat tumbuh yang khas seperti stroberi, kawista, jeruk Kintamani, anggur, dan leci. Kondisi tersebut dimungkinkan karena walaupun secara geografis pulau Bali relatif kecil, tetapi lingkungan yang sangat bervariasi dalam jarak ekologi yang pendek dan topografi yang juga bervariasi dengan kisaran ketinggian tempat dari dataran rendah sampai dataran tinggi, suhu dari suhu tropika sampai menyerupai sub-tropika, memberikan kondisi lingkungan 
yang baik sehingga spesies tanaman buah yang ada di Bali sangat banyak. Menurut Poerwanto et al. (1997), bervariasinya jenis buah yang dimiliki sangat menentukan keberhasilan dalam mengisi pasar buah secara kontinu sesuai tuntutan konsumen. Hal serupa dinyatakan oleh Swamy (2012) bahwa, dengan beragamnya jenis maka ketersediaan buah di pasaran terjadi sepanjang tahun (all year round) karena musim panen masing-masing buah berbeda waktu.

Hasil pengamatan terhadap musim panen menunjukkan, sebaran musim panen buah-buahan lokal komersial di Bali dapat dikategorikan menjadi tiga kelompok, yaitu kelompok buah yang musim panennya sepanjang tahun (tidak bermusim) seperti anggur, pepaya, pisang, melon, semangka, nangka, dan stroberi; kelompok buah yang panennya ada panen raya pada bulan tertentu dan panen kecil pada bulan lainnya seperti avokad, belimbing, jambu air, mangga, markisa, dan nangka; dan kelompok buah yang panennya ada panen raya dan panen kecil pada bulan tertentu kemudian sama sekali tidak ada panen buah pada bulan lainnya seperti duku, durian, leci, manggis, salak, jeruk, srikaya, dan wani (Tabel 2).

Kelompok buah yang musim panennya sepanjang tahun menggambarkan suplai buah dapat dilakukan setiap saat karena tanaman buah tersebut berbuah tidak mengenal musim atau karena musim panen buahnya bisa diatur dengan mengatur saat tanam, berhubung tanaman buah yang bersangkutan merupakan tanaman buah semusim.

Tabel 2. Kalender musim panen buah di Provinsi Bali

\begin{tabular}{|c|c|c|c|c|c|c|c|c|c|c|c|c|c|}
\hline \multirow{2}{*}{ No. } & \multirow{2}{*}{$\begin{array}{c}\text { Spesies } \\
\text { Tanaman }\end{array}$} & \multicolumn{12}{|c|}{ Bulan Panen/Ketersediaan Buah } \\
\hline & & 1 & 2 & 3 & 4 & 5 & 6 & 7 & 8 & 9 & 10 & 11 & 12 \\
\hline 1. & Avokad & $*$ & $* *$ & $* *$ & $* *$ & $* *$ & $*$ & $*$ & $*$ & $*$ & $*$ & $*$ & $*$ \\
\hline 2. & Anggur & $* *$ & $* *$ & $* *$ & $* *$ & $* *$ & $* *$ & $* *$ & $* *$ & $* *$ & $* *$ & $* *$ & $* *$ \\
\hline 3. & Belimbing & $* *$ & $* *$ & $* *$ & $* *$ & $* *$ & $* *$ & $* *$ & $* *$ & $*$ & $*$ & $*$ & $*$ \\
\hline 4. & Duku & $* *$ & $* *$ & $* *$ & $* *$ & $*$ & $*$ & - & - & - & - & - & - \\
\hline 5. & Durian & $* *$ & $* *$ & $* *$ & - & - & - & $*$ & $*$ & $*$ & $*$ & $* *$ & $* *$ \\
\hline 6. & Jambu air & $* *$ & $* *$ & $* *$ & $* *$ & $*$ & $*$ & $*$ & $* *$ & $* *$ & $* *$ & $* *$ & $* *$ \\
\hline 7. & Jambu biji & $* *$ & $* *$ & $* *$ & $* *$ & $* * *$ & $* * *$ & $*$ & $*$ & $*$ & $* *$ & $* *$ & $* *$ \\
\hline 8. & Pepaya & $* *$ & $* *$ & $* *$ & $* *$ & $* *$ & $* *$ & $* *$ & $* *$ & $* *$ & $* *$ & $* *$ & $* *$ \\
\hline 9. & Pisang & $* *$ & $* *$ & $* *$ & $* *$ & $* *$ & $* *$ & $* *$ & $* *$ & $* *$ & $* *$ & $* *$ & $* *$ \\
\hline 10. & Nenas & $* *$ & $* *$ & $* *$ & $* *$ & $* *$ & $* *$ & $* *$ & $* *$ & $* *$ & $* *$ & $* *$ & $* *$ \\
\hline 11. & Nangka & $*$ & $*$ & $* *$ & $* *$ & $* *$ & $* *$ & $* *$ & $* *$ & $* *$ & $* *$ & $*$ & $*$ \\
\hline 12. & Jeruk & $* *$ & $* *$ & $* *$ & - & - & - & $* *$ & $* *$ & $* *$ & - & - & - \\
\hline 13. & Jeruk Bali & $* *$ & $* *$ & $* *$ & - & - & - & - & - & - & $* *$ & $* *$ & $* *$ \\
\hline 14. & Leci & $* *$ & $* *$ & $* *$ & $*$ & - & - & - & - & - & - & - & * \\
\hline 15. & Mangga & $* *$ & $* *$ & $* *$ & $*$ & $*$ & $*$ & $*$ & $* *$ & $* *$ & $* *$ & $* *$ & $* *$ \\
\hline 16. & Manggis & $* *$ & $* *$ & $* *$ & $*$ & - & - & - & - & - & - & $*$ & * \\
\hline 17. & Markisa & $* *$ & $* *$ & $* *$ & $*$ & $*$ & $*$ & $*$ & $*$ & $*$ & $*$ & $* *$ & $* *$ \\
\hline 18. & Melon & $* *$ & $* *$ & $* *$ & $* *$ & $* *$ & $* *$ & $* *$ & $* *$ & $* *$ & $* *$ & $* *$ & $* *$ \\
\hline 19. & Rambutan & $* *$ & $* *$ & $* *$ & $*$ & $*$ & $*$ & - & - & - & - & $*$ & $* *$ \\
\hline 20. & Salak & $* *$ & $* *$ & $* *$ & $*$ & - & - & - & - & - & $*$ & $*$ & $* *$ \\
\hline 21. & Semangka & $* *$ & $* *$ & $* *$ & $* *$ & $* *$ & $* *$ & $* *$ & $* *$ & $* *$ & $* *$ & $* *$ & $* *$ \\
\hline 22. & Sirsak & $* *$ & $* *$ & $* *$ & $*$ & $*$ & $*$ & $*$ & $*$ & $*$ & $* *$ & $* *$ & $* *$ \\
\hline 23. & Srikaya & $* *$ & $* *$ & $* *$ & $*$ & - & - & - & - & - & - & $*$ & * \\
\hline 24. & Stroberi & $* *$ & $* *$ & $* *$ & $* *$ & $* *$ & $* *$ & $* *$ & $* *$ & $* *$ & $* *$ & $* *$ & $* *$ \\
\hline 25. & Sawo & $* *$ & $* *$ & $* *$ & $* *$ & $*$ & $*$ & $*$ & $* *$ & $* *$ & $* *$ & $* *$ & $* *$ \\
\hline 26. & Wani & $* *$ & $* *$ & $* *$ & $*$ & - & - & - & - & - & - & - & $*$ \\
\hline 27. & $\begin{array}{l}\text { Terung } \\
\text { Belanda }\end{array}$ & $* *$ & $* *$ & $* *$ & $*$ & $*$ & $*$ & $*$ & $*$ & $*$ & $*$ & $* *$ & $* *$ \\
\hline
\end{tabular}

Keterangan: Bulan panen 1 = Januari, $2=$ Pebruari, $3=$ Maret, $4=$ April, $5=$ Mei, $6=$ Juni, $7=$ Juli, $8=$ Agustus, $9=$ September, $10=$ Oktober, $11=$ Nopember, $12=$ Desember. $* *=$ panen raya, $*=$ panen kecil, dan $-=$ tidak ada panen. 
Kelompok buah yang panennya ada panen raya pada bulan tertentu dan panen kecil pada bulan lainnya menggambarkan ketersediaannya melimpah pada bulan-bulan tertentu tetapi suplainya sedikit di bulan yang lain, sedangkan kelompok buah yang panennya ada panen raya dan panen kecil pada bulan tertentu kemudian sama sekali tidak ada panen pada bulan lainnya menggambarkan bahwa spesies buah tersebut pada bulan tertentu sama sekali tidak ada suplai karena memang tidak ada panen sama sekali. Kelompok buah yang terakhir ini menurut Sakhidin dan Suparto (2011) menimbulkan fluktuasi ketersediaan buah dan harga. Pada saat musim panen, buah melimpah sehingga harga relatif murah, sedangkan pada saat tidak musim panen terjadi kondisi sebaliknya. Oleh karena itu, menurut Rai et al. (2010) untuk jenis buah yang pada periode tertentu sama sekali tidak ada suplai perlu dikembangkan teknologi produksi di luar musim.

Hasil analisis menggunakan metode LQ (location quotient) menunjukkan, setiap kabupaten di Bali memiliki spesies buah lokal komersial unggulan yang relatif berbeda (Tabel 3). Kabupaten Jembrana yang terkenal sebagai salah satu kabupaten sentra produksi pisang memiliki 4 spesies buah unggulan, yaitu pisang, semangka, melon, dan nenas. Buah unggulan Kabupaten Tabanan terdiri atas 6 spesies, yaitu rambutan, durian, semangka, sawo, pepaya, dan pisang, sedangkan buah unggulan Kabupeten Badung terdiri atas 5 spesies, yaitu avokad, nangka, jambu biji, semangka, dan pepaya. Kabupaten Gianyar dan Kabupaten Klungkung yang oleh masyarakat tidak dikenal sebagai penghasil buah spesifik ternyata tergolong kabupaten yang memiliki buah unggulan paling banyak, yaitu masing-masing sebanyak 8 spesies buah. Buah unggulan di Kabupaten Gianyar yaitu avokad, rambutan, jeruk, durian, jambu biji, semangka, melon, dan pepaya, sedangkan buang unggulan Kabupaten Klungkung yaitu avokad, mangga, durian, jambu biji, sawo, pepaya, pisang, dan nenas.

Kabupaten Bangli yang terkenal sebagai sentra penghasil jeruk di Bali hanya memiliki 2 spesies buah unggulan yaitu jeruk dan pisang, sementara Kabupaten Karangasem yang terkenal sebagai sentra produksi salak memiliki 7 spesies buah unggulan, yaitu mangga, nangka, jambu biji, sawo, pepaya, nenas, dan salak. Selanjutnya, Kabupaten Buleleng yang terkenal dengan buah anggur dan durian, memiliki 6 spesies buah unggulan yaitu avokad, mangga, rambutan, durian, sawo, dan anggur. Menurut Hendrayana (2003), penentuan komoditas unggulan merupakan langkah awal yang sangat penting menuju pembangunan pertanian yang berpijak pada efisiensi untuk meraih keunggulan komparatif dan kompetetif agar bisa memenuhi permintaan pasar.

Tabel 3. Komoditas buah unggulan di masing-masing Kabupaten di Bali

\begin{tabular}{|c|c|c|c|c|c|c|c|c|c|}
\hline No & $\begin{array}{l}\text { Nama } \\
\text { Buah }\end{array}$ & $\begin{array}{l}\text { Jem- } \\
\text { brana }\end{array}$ & $\begin{array}{l}\text { Taba- } \\
\text { nan }\end{array}$ & Badung & Gianyar & $\begin{array}{l}\text { Klung- } \\
\text { kung }\end{array}$ & Bangli & $\begin{array}{l}\text { Karang } \\
\text { asem }\end{array}$ & $\begin{array}{l}\text { Bule- } \\
\text { leng }\end{array}$ \\
\hline 1. & Avokad & 0.03 & 0.73 & $2.11^{* *}$ & $2.66^{* *}$ & $2.81^{* * *}$ & 0.60 & 0.81 & $1.80^{* * *}$ \\
\hline 2. & Mangga & 0.90 & 0.38 & 0.50 & 0.64 & $2.73^{* * *}$ & 0.08 & $1.35^{* *}$ & $3.23^{* * *}$ \\
\hline 3. & Rambutan & 0.59 & $1.80^{* *}$ & 0.27 & $1.12^{* * *}$ & 0.87 & 0.04 & 0.23 & $4.66^{* *}$ \\
\hline 4. & Nangka & 0.09 & 0.68 & $4.69^{* *}$ & 0.71 & 0.63 & 0.44 & $2.15^{* *}$ & 0.55 \\
\hline 5. & Jeruk & 0.03 & 0.06 & 0.67 & $1.39^{* * *}$ & 0.05 & $1.71^{* *}$ & 0.01 & 0.16 \\
\hline 6. & Durian & 0.21 & $7.29^{* *}$ & $3.04^{\text {** }}$ & $2.29^{* *}$ & $1.95^{* *}$ & 0.22 & 0.76 & $1.49^{\text {*** }}$ \\
\hline 7. & Jambu biji & 0.25 & 0.96 & $1.69^{* *}$ & $4.88^{* *}$ & $4.85^{* *}$ & 0.36 & $5.02^{* *}$ & 0.55 \\
\hline 8. & Semangka & $7.09^{* *}$ & $2.24^{* *}$ & $2.79^{* *}$ & $1.57^{* *}$ & 0.08 & 0.00 & 0.02 & 0.16 \\
\hline 9. & Melon & $6.53^{* *}$ & 0.00 & 0.16 & $3.58^{* *}$ & 0.00 & 0.00 & 0.24 & 0.74 \\
\hline 10. & Sawo & 0.54 & $2.34^{* *}$ & 0.63 & 0.70 & $3.64^{* * *}$ & 0.04 & $2.60^{* *}$ & $1.42^{* *}$ \\
\hline 11. & Pepaya & 0.38 & $1.62^{* *}$ & $1.07^{* *}$ & $2.88^{* *}$ & $2.82^{* * *}$ & 0.72 & $1.43^{* *}$ & 0.77 \\
\hline 12. & Pisang & $1.73^{* *}$ & $1.41^{* *}$ & 0.77 & 0.79 & $1.40^{* * *}$ & $1.30^{* *}$ & 0.50 & 0.82 \\
\hline 13. & Nenas & $2.81^{* *}$ & 0.96 & 0.95 & 0.80 & $3.31^{* * *}$ & 0.74 & $1.80^{* *}$ & 0.13 \\
\hline 14. & Salak & 0.01 & 0.29 & 0.03 & 0.06 & 0.07 & 0.22 & $5.97^{* * *}$ & 0.05 \\
\hline 15. & Anggur & 0.00 & 0.00 & 0.00 & 0.00 & 0.00 & 0.00 & 0.00 & $6.06^{* * *}$ \\
\hline
\end{tabular}

Keterangan: ${ }^{* *}$ Komoditas buah unggulan kabupaten dengan nilai LQ $\geq 1$. 
Dalam upaya meningkatkan pemanfaatan buah-buahan lokal untuk pasar pariwisata, penetapan buah unggulan kabupaten atau bahkan kecamatan dan desa menjadi sangat penting untuk memudahkan pembinaan bagi produsen buah agar dapat menghasilkan produk berkualitas sacara berkesinambungan sesuai tuntutan pasar pariwisata. Di sisi lain, pasar pariwisata akan lebih mudah mendapatkan buah dengan terkonsentrasinya pengembangan buah sesuai potensi wilayah. Adanya penetapan wilayah dengan komoditas buah unggulan juga memudahkan terciptanya hubungan produsen-konsumen antara petani buah-buahan dengan pasar pariwisata. Hal ini sesuai dengan pendapat Kidd (2011), bahwa keberhasilan pengembangan pertanian agar bersinergi dengan pariwisata sangat dipengaruhi oleh faktor fisik lahan, kebijakan, tingkat supply dan demand, kemudahan interaksi dan aksesibilitas.

\section{KESIMPULAN}

Berdasarkan hasil penelitian ini dapat disimpulkan teridentifikasi 41 spesies dan 149 sub-spesies buah-buahan lokal di Bali. Lokasi tumbuhnya sebagian besar tersebar hampir di seluruh kabupaten/kota, tetapi ada yang hanya dibudidayakan atau tumbuh pada lokasi spesifik tertentu. Ketersediaan buah-buahan lokal umumnya bersifat musiman, dengan musim panen dominan dari bulan Desember sampai Maret. Pemanfaatan buah-buahan lokal Bali adalah untuk konsumsi lokal, perdagangan antar pulau, ekspor, memenuhi keperluan ritual adat dan budaya dan pasar pariwisata. Pemanfaatan untuk kegiatan pariwisata masih relatif terbatas, yaitu dalam bentuk hasil buah untuk konsumsi segar (fresh fruit), hasil buah untuk bahan juice, hasil buah untuk bahan wine, bagian buah, daun, atau bagian lainnya untuk massage/spa, dan kebun buah-buahan untuk agrowisata. Berdasarkan hasil penelitian ini perlu ada upaya nyata meningkatkan pemanfaatan buah-buahan lokal untuk pariwisata agar kesejahteraan masyarakat petani di Bali semakin meningkat.

\section{DAFTAR PUSTAKA}

Adelianie, I.G.A.D. 2015. Penyajian buah lokal dalam operasional hotel berbintang di Kawasan Pariwisata Sanur. Thesis. Program Magister, Program Studi Kajian Pariwisata, Program Pascasarjana Universitas Udayana. 134 hal.

[BPS] Biro Pusat Statistik Bali. 2014. Bali dalam Angka 2013. Biro Pusat Statistik Provinsi Bali.

Budiarti, T., Suwarto, I. Muflikhati. 2013. Pengembangan agrowisata berbasis masyarakat pada usahatani terpadu guna meningkatkan kesejahteraan petani dan keberlanjutan sistem pertanian. J. Ilmu Pertanian Indonesia. 18(3): 200-207.

Budiarti, T., A.D. Listyanti. 2015 Development of community-based agritourism on integrated farming system toward sustainable village. Australian J. Basic Applied. Sci. 9(7): 242-244.

Dinata, I.K.K., I.K. Sardiana, N.W. Siti. 2011. Pemberdayaan potensi masyarakat dalam pengembangan pariwisata berbasis pertanian di Bali. Majalah Aplikasi Ipteks Ngayah. 2(2): 67-77.

Gardenfors, U., C. Hilton-Taylor, G. Mace, J.P. Rodríguez. 2001. The application of IUCN Red List criteria at regional levels. Conservation Biology. 15: 12061212.

Goodwin, H. 2008. Tourism, local economic development, and poverty reduction. J. Applied Research Economic Dev.. 5(3): 55-64.

Hendrayana, R. 2003. Aplikasi metode Location Quotient (LQ) dalam penentuan komoditas unggulan nasional. Informatika Pertanian. 12(1): 1-13. 
Isserman, A.M. 1977. The Location Quotient approach to estimating regional economic impacts. J. the American Planning Association. 43(1): 33-41.

Kidd, J. 2011. Hospitality on the farm: the development of a systems model of farm tourism. Asean J. Hospitality and Tourism. 10(1): 17-25.

Mace, G.M., R. Lande. 1991. Assessing extinction threats: toward a reevaluation of IUCN threatened species categories. Conservation Biology. 5: 148-157.

Miller, M.M., J.L. Gibson, G.N. Wright. 1991. Location Quotient: basic tools for economic development studies. Economic Development Review. 9(2): 65-68.

Milner-Gulland, E.J. 1992. The Development of new criteria for listing species on the IUCN (International Union for the Conservation of Nature and Natural Resources) Red List. Species. 19: 16-22.

Nurisjah, S. 2001. Pengembangan kawasan wisata agro (Agrotourism). Buletin Tanaman dan Lanskap Indonesia. 4(2): 20-23.

Poerwanto, R., D. Effendi, S.S. Harjadi. 1997. Pengaturan pembungaan mangga Gadung 21 di luar musim dengan paklobutrazol dan zat pemecah domansi. Hayati. 4(2): 41-46.

Prayogi, A., H.K. Yuni. 2013. Pengembangan aktifitas pertanian sebagai alternatif pengembangan wisata di Bali. J. Perhotelan dan Pariwisata. 3(2): 57-68.

Rai, I.N., C.G.A Semarajaya, I.W. Wiraatmaja. 2010. Studi fenofisiologi pembungaan salak Gula Pasir sebagai upaya mengatasi kegagalan Fruit-Set. J. Hortikultura. 20(3): 216-222.

Routray, J.K., S.H.P. Malkanthi. 2011. Agritourism development: the case of Sri Lanka. Asean J. Hospitality and Tourism. 10(1): 3-15.

Sakhidin, S., R. Suparto. 2011. Kandungan giberelin, kinetin, dan asam absisat pada tanaman durian yang diberi Paklobutrazol dan Etepon. J. Hort. Indonesia. 2(1): 21-26.

Sudana, I.P., N.P.E. Mahadewi. 2015. Pelatihan mengkemas paket agrowisata bagi anggota kelompok tani di Desa Kerta, Kecamatan Payangan, Kabupaten Gianyar. Udayana Mengabdi. 14(1): 4245.

Sumiyati, L. Sutiarso, I.W. Windia, P. Sudira. 2011. Aplikasi analytical hierarchy process (AHP) untuk penentuan strategi pengembangan subak. Agritech. 31(2): 138-145.

Suyastri, N.M.Y.P. 2012. Pemberdayaan subak melalui "Green Tourism" mendukung keberlanjutan pembangunan pertanian di Bali. Jurnal SEPA (Sosial Ekonomi Pertanian dan Agribisnis). 8(2): 168-173.

Swamy, J.S. 2012. Flowering manipulation in manggo. J. Today's Biological Sciences: Research and Review. 1(1): 122-127.

Windia, W., M. Wirartha, K. Suamba, M. Sarjana. 2011. Model pengembangan agrowisata berbasis subak di Bali. J. Socio-economic of Agriculture and Agribusiness. 11(1): 81-86. 